\title{
The validity and reliability of the Thai version of the asthma control test
}

\author{
Nutchanok Niyatiwatchanchai, Warawut Chaiwong, Chaicharn Pothirat
}

\begin{abstract}
Background: The Asthma Control Test (ACT) has been widely used for the assessment of asthma control. However, it has never been validated in adult Thai asthmatic patients.
\end{abstract}

Objective: To determine the validity and reliability of the Thai version of the ACT in adult Thai asthmatic patients.

Methods: Any correlation between ACT and level of asthma controlled was determined using the Spearman's rank correlation coefficient. The ACT was carried out at 2 visits to a physician (4-12 weeks apart) to ascertain the level of reliability. Discriminant validity was determined using an area under receiver operating characteristic curve (AuROC) to identify the optimum cut-off point of the levels of control.

Results: Seventy-one asthmatic adult patients, 40 (56.3\%) female with a mean age of $54.2 \pm 14.7$ years were enrolled. The Thai version of ACT showed an acceptable internal consistency reliability with a Cronbach's alpha $=0.75$. Test-retest reliability was 0.82 . There was a significant correlation between the ACT scores and GINA symptom control tool $(r$ $=0.87, p<0.001)$. An ACT $\leq 22$ was used to screen "not well-controlled" asthma with a sensitivity of $96.4 \%$ and specificity of $93.0 \%$ and an ACT score $\leq 19$ was used to screen "uncontrolled" asthma.

Conclusion: The Thai version of ACT is valid and a reliable tool for use in adult Thai asthmatic patients. However, the cut off points of ACT for levels of control should be changed to 22 and 19 for differentiation between well vs. partly controlled and partly vs. uncontrolled asthma, respectively.

Key words: asthma, control, validation, reliability, Thai

\section{From:}

Division of Pulmonary, Critical Care and Allergy,

Department of Internal Medicine, Faculty of Medicine,

Chiang Mai University, Chiang Mai, Thailand

\section{Introduction}

Asthma is associated with high morbidity, mortality and economic burden despite recent advances in the perceiving of pathophysiology and availability of new effective treatment. The prevalence of asthma in Thai adults is estimated to be between 3 and 4\%. ${ }^{1,2}$ Most patients under-report asthma symptoms and receive suboptimal care, resulting in poor control. ${ }^{3,4}$ Only $8 \%$ of asthmatic adults and adolescents in Thailand were classified as having controlled asthma. ${ }^{5}$

The goals of asthma therapy are the achievement and maintenance of asthma control for prolonged periods with safe treatment. "Asthma control" refers to the extent to which the manifestations of asthma have been reduced or removed by treatment. ${ }^{6}$ Recent Global Initiative for Asthma (GINA)
Corresponding author:

Chaicharn Pothirat

110 Inthavaroros Rd. Sriphum, Maung Chiang Mai,

Chiang Mai, 50200 Thailand

E-mail: chaicharn.p@cmu.ac.th

guidelines focus on the level of control more than the severity of the disease. Assessment of asthma control consists of two domains including symptom control and future risk of adverse outcomes. ${ }^{7}$ The guidelines emphasize the need for periodic assessment to achieve controlled asthma once treatment is established. ${ }^{4}$

In Thailand, GINA guidelines have been used as a standard recommendation for asthma management. Asthma control assessment by GINA requires lung function as a part of the assessment. It is difficult to follow the guidelines completely because it is burdensome and also it takes time to carry out spirometry in all patients at a busy outpatient clinic. In developing countries, especially, there are limits 
to the availability of spirometry and skilled technicians. There are many tests which have been developed for the assessment of asthma control, one of them is the Asthma Control Test (ACT), a useful tool which is straightforward to employ. ACT was developed in 2004 and became the most widely used tool for assessing asthma control. ${ }^{8}$ ACT is a patient-centered/completed questionnaire about patients' symptoms and the perception of the level of control over the previous 4 weeks. The questionnaire consists of 5 questions: including asthma symptoms (daytime and nocturnal), the use of rescue medications, the limitation of activity due to asthma, and the patient's perception of asthma control. ACT has been translated and validated in many countries and in different settings. ${ }^{49-15}$ ACT is a good evaluative and discriminative tool for the assessment of asthma control for outpatients. Previous studies have shown a strong correlation between the ACT and the Asthma Control Questionnaire (ACQ). ${ }^{9}{ }^{916}$ A significant correlation between ACT and the Asthma Quality of Life Questionnaire (AQLQ) has also been reported in previous studies. ${ }^{17}$ However, ACT has moderate to low correlation with forced expiratory volume in the first second $\left(\mathrm{FEV}_{1}\right)$. $8,12,18$

ACT has been translated into Thai and used extensively in many clinical settings in Thailand for many years. The Thai version of childhood asthma control test (C-ACT) was validated for children 4 to 11 years and the cut values of C-ACT for detection of well-controlled asthma was mentioned. ${ }^{19}$ However, this tool has never been validated in Thai adult asthmatic patients. Therefore, the primary objective of this study was to evaluate the reliability and establish the validity of the Thai version of the ACT. The secondary objective was to identify the optimum cut-off points of ACT for levels of asthma control.

\section{Methods \\ Study design}

This prospective observational study was conducted at the outpatient asthma clinic at Maharaj Nakorn Chiang Mai Hospital, a tertiary care hospital in Northern Thailand, Chiang Mai, Thailand from June to November 2019. The protocol was approved by the Research Ethics Committee of the Faculty of Medicine, Chiang Mai University [Institutional Review Board (IRB) approval number: MED-2562-06285, date of approval: 28/05/2018].

\section{Study population}

The study included asthmatic patients older than 18 years old who attended our outpatient asthma clinic. The asthma diagnosis was based on GINA guidelines using patient history and confirmed variable respiratory airflow limitation. ${ }^{7}$ We excluded patients who had had an asthma attack or were hospitalized for acute upper or lower respiratory tract infection within the 4 weeks prior to enrollment, had coexisting pulmonary disease, had smoked 10 or more pack-years, or were pregnant. All subjects provided written informed consent.

\section{Data collection}

The ACT is a 5-item questionnaire designed for the selfassessment of asthma symptoms and perception of control. ${ }^{8}$
Each item includes five response options with values ranging from 1 to 5 . The summation score of 5 items yields a score ranging from 5 (poor control of asthma) to 25 (complete control of asthma). ${ }^{8}$ The Thai version of ACT was translated by GlaxoSmithKline and used in clinical practice for many years.

We arranged two scheduled physician visits separated by 4 to 12 weeks (baseline and follow-up visit) for each patient. At each visit, patients completed an ACT questionnaire and underwent spirometry. Then, the physician interviewed and assessed the patients in accordance with the asthma control base described in the GINA guidelines. The classifications being: controlled, partly controlled and uncontrolled asthma. The physician was blinded to the ACT score during the assessment.

\section{Sample size calculation}

Based on a previous study, the correlation between the ACT and the rating of the control of asthma by a physician was 0.52. An ACT of 19 was used as the cut-point score of uncontrolled asthma with the highest area under receiver operating characteristic curve (AuROC), $\mathrm{AUC}=0.71 .^{9}$ The sample size for the study needed to be at least 56 subjects to give a power $=0.9$ with statistical significance set at $<0.05$.

\section{Statistical analysis}

Baseline characteristics are described using descriptive statistics. Results for numerical data are expressed as mean \pm standard deviation (SD) or median and interquartile range (IQR) as appropriate. Results with proportion are expressed as frequencies and percentages. Cronbach's alpha was used to determine the internal consistency with regard to the reliability of the five items of the ACT questionnaires. Test-retest reliability of ACT was assessed by intraclass correlation (ICC) between the 2 visits in stable patients. Concurrent validity of ACT score was evaluated using Spearman's rank correlation coefficient between ACT score and level of asthma control defined by GINA at the baseline visit. Discriminant validity was evaluated using the Kruskal Wallis test to determine known group validity by comparing median ACT score at the baseline visit between three groups of patients by GINA classification. The accuracy of ACT as a tool for detection of "not well-controlled" asthma and "controlled" asthma was determined using sensitivity, specificity, positive predictive value $(\mathrm{PPV})$, negative predictive value (NPV), Youden's index and area under receiver operating characteristic curve (AuROC) from various points of the ACT score to identify the optimum cut-off point.

\section{Results}

Eighty-five asthmatic patients were enrolled onto the study and seventy-one patients met the inclusion criteria. The mean age of patients was $54.2 \pm 14.7$ years old and 40 patients (56.3\%) were female. Approximately a quarter of patients (26.8\%) had a history of asthma exacerbation in the previous year. At the baseline visit, the mean percentage predicted $\mathrm{FEV}_{1}$ was $80.7 \pm 20.7$ and the mean total ACT score was 22.1 \pm 3.1. More details are shown in table 1 . 
Table 1. Demographic data of all subjects

\begin{tabular}{|c|c|}
\hline Parameters & $\begin{array}{c}\text { Mean } \pm \text { SD or } \\
\text { Number } \mathbf{n}(\%) \\
\mathbf{N}=71\end{array}$ \\
\hline Age (years) & $54.2 \pm 14.7$ \\
\hline Female & $40(56.3)$ \\
\hline BMI $\left(\mathrm{kg} / \mathrm{m}^{2}\right)$ & $26.4 \pm 4.8$ \\
\hline Age of onset of asthma, median (IQR) (years) & $29(16,47)$ \\
\hline$\%$ predicted $\mathrm{FEV}_{1}$ & $80.7 \pm 20.7$ \\
\hline Total ACT score & $22.1 \pm 3.1$ \\
\hline History of smoking (yes) & $11(15.5)$ \\
\hline Family history of asthma (yes) & $24(33.8)$ \\
\hline History of intubation (yes) & $10(14.1)$ \\
\hline History of AE in the previous year & $19(26.8)$ \\
\hline Correct inhalation technique used & $23(32.4)$ \\
\hline \multicolumn{2}{|l|}{ Current medications } \\
\hline SABA & $3(4.2)$ \\
\hline ICS alone & $1(1.4)$ \\
\hline ICS/LABA & $51(71.8)$ \\
\hline ICS/LABA and LAMA & $9(12.7)$ \\
\hline ICS/LABA, LAMA and biologics & $4(5.6)$ \\
\hline Others & $3(4.2)$ \\
\hline \multicolumn{2}{|l|}{ Daily dose of ICS $(n=65)$} \\
\hline Low & $20(30.8)$ \\
\hline Medium & $32(49.2)$ \\
\hline High & $13(20.0)$ \\
\hline
\end{tabular}

Abbreviations: $\mathrm{BMI}$, body mass index; $\mathrm{IQR}$, interquartile range; $\mathrm{FEV}_{1}$, forced expiratory volume in the first second; ACT, Asthma Control Test; AE, acute exacerbation; SABA, short acting beta agonists; LABA, long acting beta agonist; ICS, inhaled corticosteroid; LAMA, long acting muscarinic antagonists.

\section{Reliability}

The Thai version of ACT had an internal consistency of 0.75 , indicating an acceptable level of consistency between the five questions on the ACT questionnaire. The test-retest reliability between the 2 visits of forty-one stable patients showed an ICC of 0.82 therefore was judged acceptable.

\section{Concurrent validity}

There was a statistically significant strong correlation between ACT score and level of asthma symptom control defined by GINA at the baseline visit $(r=0.87, p<0001)$ (Figure 1). ACT score does not have correlation with percent predicted of $\mathrm{FEV}_{1}$ and ratio of $\mathrm{FEV}_{1}$ to $\mathrm{FVC}$ as demonstrated by Spearman's correlation $(r=-0.04, p=0.724$ and $r=-0.06$, $p=0.591$, respectively).

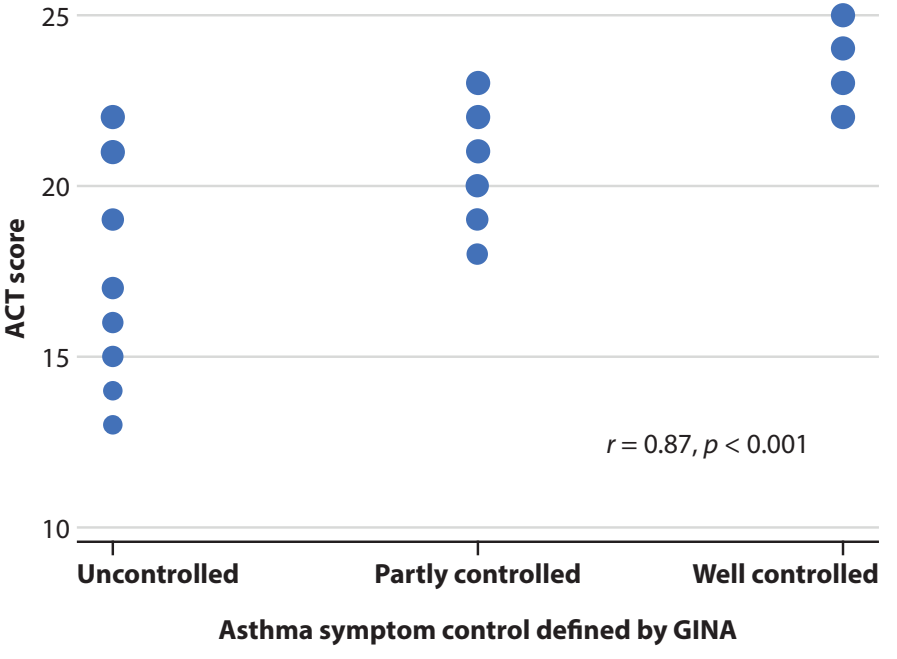

Figure 1. Correlation between ACT score and level of asthma symptom control defined by GINA at baseline visit.

Note: The dot sizes were weighted by the repeated of ACT score.

\section{Discriminant validity}

There were significant differences in the median ACT score across the three groups of asthma control classified by GINA $(p=0.006)$. The median ACT score was lowest and highest in patients in the uncontrolled group and controlled group, respectively (Figure 2 ).

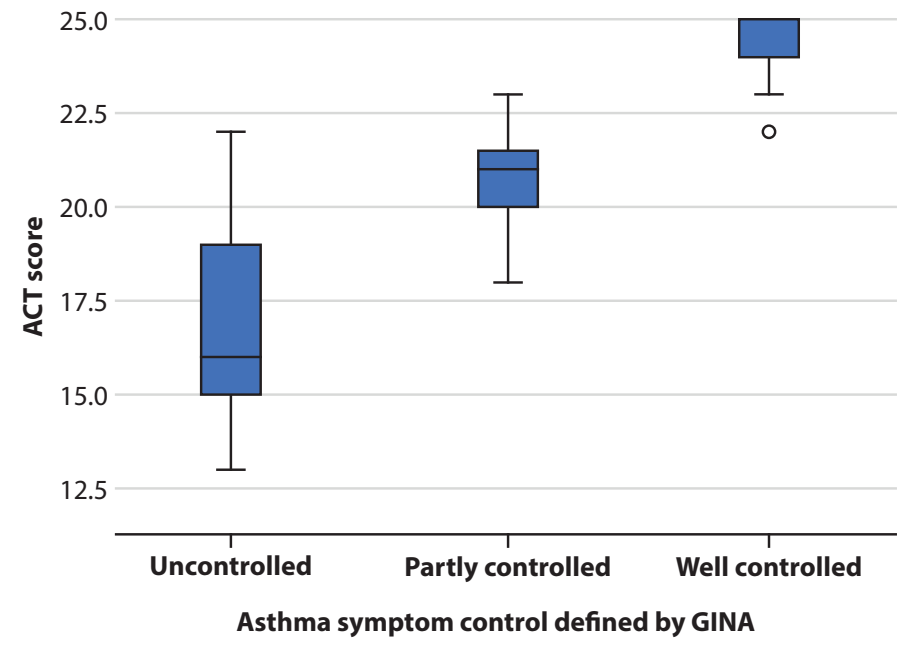

Figure 2. Difference in median ACT score across the three groups defined by GINA symptom control

Note: Horizontal lines represent median values. The top and the bottom end of the box represent the upper quartile and the lower quartile, respectively. Abbreviations: ACT, Asthma Control Test; GINA, Global Initiative for Asthma

\section{Accuracy in screening for "not well-controlled" asthma}

The efficacy of the Thai ACT score for the detection of "not well-controlled" asthma (uncontrolled and partly controlled) across various cut-point scores of ACT is summarized in Table 2. The cut-point score of $\leq 22$ had the highest AuROC with a sensitivity of $96.4 \%$, a specificity of $93.0 \%$, PPV of $90.0 \%$, NPV of $97.6 \%$ and a Youden's index of 0.89 . 
Table 2. Performance of the ACT score at different cut-off points for detecting the GINA category of not well-controlled asthma [not well-controlled (partly controlled/uncontrolled) vs. controlled] $(\mathrm{N}=71)$

\begin{tabular}{|c|c|c|c|c|c|c|}
\hline $\begin{array}{l}\text { ACT } \\
\text { score }\end{array}$ & $\begin{array}{c}\text { Sensitiv- } \\
\text { ity }(\%)\end{array}$ & $\begin{array}{c}\text { Specifici- } \\
\text { ty }(\%)\end{array}$ & $\begin{array}{l}\text { PPV } \\
(\%)\end{array}$ & $\begin{array}{c}\text { NPV } \\
(\%)\end{array}$ & $\begin{array}{c}\text { Youden's } \\
\text { Index }\end{array}$ & AUC \\
\hline$\leq 13$ & 3.6 & 100.0 & 100.0 & 61.4 & 0.04 & 0.52 \\
\hline$\leq 14$ & 7.1 & 100.0 & 100.0 & 62.3 & 0.07 & 0.54 \\
\hline$\leq 15$ & 14.3 & 100.0 & 100.0 & 64.2 & 0.14 & 0.57 \\
\hline$\leq 16$ & 25.0 & 100.0 & 100.0 & 67.2 & 0.25 & 0.63 \\
\hline$\leq 17$ & 32.1 & 100.0 & 100.0 & 69.4 & 0.32 & 0.66 \\
\hline$\leq 18$ & 35.7 & 100.0 & 100.0 & 70.5 & 0.36 & 0.68 \\
\hline$\leq 19$ & 46.4 & 100.0 & 100.0 & 74.1 & 0.46 & 0.73 \\
\hline$\leq 20$ & 60.7 & 100.0 & 100.0 & 79.6 & 0.61 & 0.80 \\
\hline$\leq 21$ & 82.1 & 100.0 & 100.0 & 89.6 & 0.82 & 0.91 \\
\hline$\leq \mathbf{2 2}$ & $\underline{96.4}$ & $\underline{93.0}$ & $\underline{90.0}$ & $\underline{97.6}$ & $\underline{0.89}$ & $\underline{0.95}$ \\
\hline$\leq 23$ & 100.0 & 83.7 & 80.0 & 100.0 & 0.84 & 0.92 \\
\hline$\leq 24$ & 100.0 & 30.2 & 48.3 & 100.0 & 0.30 & 0.65 \\
\hline
\end{tabular}

Abbreviations: ACT, Asthma Control Test; PPV, positive predictive value; NPV, negative predictive value; AUC, area under the curve

ROC for identifying not well-controlled asthma as defined by the GINA 2016 classification using ACT is shown in Figure 3. A cut-point of 22 was closest to the top corner of the curve with an $\mathrm{AuROC}=0.99$ (95\%CI; 0.98, 1.00).

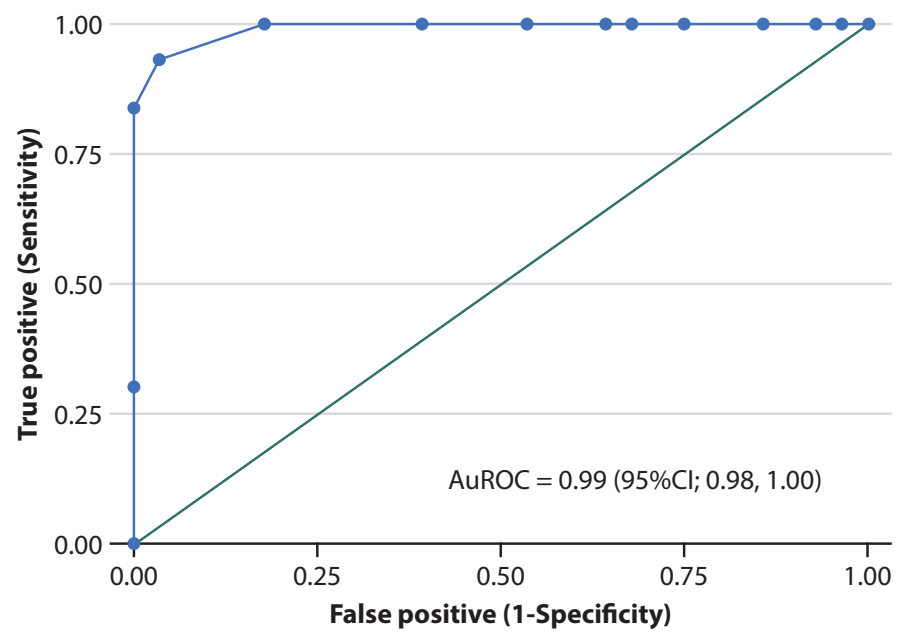

Figure 3. ROC for identifying not well-controlled asthma as defined by GINA 2016 classification using ACT

Only subjects with "not well-controlled" asthma were included for evaluation of a cutoff ACT score between partly controlled and uncontrolled asthma. The cut-point score of $\leq$ 19 had the highest AuROC with a sensitivity of $84.6 \%$, specificity of $86.7 \%$, PPV of $84.6 \%$, NPV of $86.7 \%$ and a Youden's index of 0.71 (Table 3).
Table 3. Performance of the ACT score at different cut-off points for detecting the GINA category of partly controlled asthma vs. uncontrolled $(n=28)$.

\begin{tabular}{lcccccc}
$\begin{array}{c}\text { ACT } \\
\text { score }\end{array}$ & $\begin{array}{c}\text { Sensitiv- } \\
\text { ity (\%) }\end{array}$ & $\begin{array}{c}\text { Specifici- } \\
\text { ty (\%) }\end{array}$ & $\begin{array}{c}\text { PPV } \\
(\%)\end{array}$ & $\begin{array}{c}\text { NPV } \\
(\%)\end{array}$ & $\begin{array}{c}\text { Youden's } \\
\text { Index }\end{array}$ & AUC \\
$\leq 13$ & 7.7 & 100.0 & 100.0 & 55.6 & 0.08 & 0.54 \\
$\leq 14$ & 15.4 & 100.0 & 100.0 & 57.7 & 0.15 & 0.58 \\
$\leq 15$ & 30.8 & 100.0 & 100.0 & 62.5 & 0.31 & 0.65 \\
$\leq 16$ & 53.8 & 100.0 & 100.0 & 71.4 & 0.54 & 0.77 \\
$\leq 17$ & 69.2 & 100.0 & 100.0 & 78.9 & 0.69 & 0.85 \\
$\leq 18$ & 69.2 & 93.3 & 90.0 & 77.8 & 0.63 & 0.81 \\
$\leq 19$ & $\underline{\mathbf{8 4 . 6}}$ & $\underline{\mathbf{8 6 . 7}}$ & $\underline{\mathbf{8 4 . 6}}$ & $\underline{\mathbf{8 6 . 7}}$ & $\underline{\mathbf{0 . 7 1}}$ & $\underline{\mathbf{0 . 8 6}}$ \\
$\leq 20$ & 84.6 & 60.0 & 64.7 & 81.8 & 0.45 & 0.72 \\
$\leq 21$ & 92.3 & 26.7 & 52.2 & 80.0 & 0.19 & 0.59 \\
$\leq 22$ & 100 & 6.7 & 48.1 & 100.0 & 0.07 & 0.53 \\
\hline
\end{tabular}

Abbreviations: ACT, Asthma Control Test; PPV, positive predictive value; $\mathrm{NPV}$, negative predictive value; AUC, area under the curve

\section{Discussion}

This prospective observational study demonstrated that the Thai version of ACT score had an acceptable level of reliability and validity for Thai adult asthma patients. Our study showed an acceptable internal consistency with a Cronbach's alpha of 0.75 . Our results were comparable to the previous studies investigating the original version and other language versions of the ACT score with a range from 0.72 to $0.85 .^{8-}$ ${ }^{12,14,20}$ In the case of test-retest reliability which had an ICC in this study of 0.82 , the results were supported by previous findings which had a range of 0.77-0.93.9,10,14,20,21 For concurrent validity, we found a strong correlation between the ACT score and GINA based assessment $(r=0.87, p<0.001)$ which again corresponded with the findings of previous studies (correlation coefficient ( $r$ ) ranged from 0.45 to 0.89 ). ${ }^{8,9,11,14,20}$

In terms of cut-off points of ACT score for detection of level of asthma control, our study found that an ACT of 22 or less had an optimal balance of sensitivity (96.4\%) and specificity (93.0\%) with the best AUC (0.95) for differentiation between "well-" and "not well" controlled asthma. Moreover, we also showed that the value of 19 as a cut-off point of ACT had the highest AUC (0.86) for differentiation between "partly" and "uncontrolled" asthma. The goal for asthma therapy is controlled or completely controlled asthma, so our aim is to screen all patients which were "not well-controlled" to optimize their treatment. This was in contrast to many of the previous studies ${ }^{8,9,11,12,14}$ which only aimed to screen "uncontrolled asthma" and did not include partly controlled asthma. Therefore, the ACT score from previous studies (original: 19, USA: 19, China: 19, Vietnam: 19, Turkey: 19) was lower than ours. However, our cut off-point $(\mathrm{ACT} \leq 22)$ was similar to that reported by a study carried out in Japan, ${ }^{22}$ which suggested that an ACT of 23 or more was an optimal cut-off point for identifying well-controlled asthma. 
Our study has several limitations. Firstly, the survey was conducted in a single center in the northern part of Thailand therefore the results may not be directly transferrable across ethnicity and geographical location. Also, the mean age of the patients in this study was higher than that in general asthma populations, therefore; again, the findings may not be generalized to all age groups of adult asthma in Thailand. The local language is widely used in northern Thailand, especially in the elderly, but the Thai version of ACT was translated into formal Thai language. This could pose a language barrier. This finding may be not applicable to all asthma patients especially the area that has local language. Therefore, the multicenter studies that include Thai people from every parts of Thailand should be done to confirm the validity of Thai ACT. Moreover, dialectal version of ACT score should also be validated and compare with the formal version as had been done in chronic obstructive pulmonary disease assessment test. ${ }^{23}$ In addition, there was a patient selection bias as we enrolled only participants from a specialist clinic. Therefore, the results may not be generalized to all asthma patients in other settings such as those being treated in a general practitioner clinic or general internal medicine clinic. The study of Thai ACT validity in those settings should be done as validation of ACT in Chinese primary care settings. ${ }^{24}$ The correlation between ACT and physician rating was higher in teaching hospitals than in primary setting. This finding could be from better education of the enrolled patients in teaching hospitals. Finally, we did not have the true gold standard test for assessing asthma control. However, the asthma control level based on the GINA guidelines (well controlled, partly controlled and uncontrolled asthma) was used in the previous studies therefore our findings are comparable on that level. ${ }^{12,14,21}$

\section{Conclusion}

The Thai version of the ACT score is reliable and is a valid tool for the evaluation of asthma control and the ACT score cut points of 22 and 19 could be used to differentiate between "well" vs. "partly" and "partly" vs. "uncontrolled" asthma in cases of Thai adult asthma.

\section{Acknowledgments}

The authors wish to record their thanks to all patients who participated in this study and to the staff members of the Division of Pulmonary, Critical Care and Allergy, Department of Internal Medicine, Faculty of Medicine, Chiang Mai University for their vital contributions to this investigation.

\section{Author Contributions}

Conceptualization, N.N., C.P., and W.C.; Methodology, N.N., C.P., and W.C.; Validation, N.N. and C.P.; Formal Analysis, N.N., C.P., and W.C.; Investigation, N.N. and C.P.; Data Curation, N.N., C.P., and W.C.; Writing - Original Draft Preparation, N.N.; Writing - Review \& Editing, N.N., C.P., and W.C.; Visualization, N.N. and C.P.; Supervision, C.P.; Project Administration, C.P.; All authors have read and agreed to the published version of the manuscript.

\section{Disclosure Statement}

Conceptualization, N.N., C.P., and W.C.; Methodology, N.N., C.P., and W.C.; Validation, N.N. and C.P.; Formal Analysis, N.N., C.P., and W.C.; Investigation, N.N. and C.P.; Data Curation, N.N., C.P., and W.C.; Writing - Original Draft Preparation, N.N.; Writing - Review \& Editing, N.N., C.P., and W.C.; Visualization, N.N. and C.P.; Supervision, C.P.; Project Administration, C.P.; All authors have read and agreed to the published version of the manuscript.

\section{References}

1. Boonsawat W, Charoenphan P, Kiatboonsri S, Wongtim S, Viriyachaiyo V, Pothirat C, et al. Survey of asthma control in Thailand. Respirology. 2004;9(3):373-8.

2. Dejsomritrutai W, Nana A, Chierakul N, Tscheikuna J, Sompradeekul S, Ruttanaumpawan P, et al. Prevalence of Bronchial Hyperresponsiveness and Asthma in the Adult Population in Thailand. Chest. 2006;129(3):602-9.

3. Revicki D, Weiss KB. Clinical assessment of asthma symptom control: review of current assessment instruments. J Asthma. 2006;43(7):481-7.

4. Alzahrani YA, Becker EA. Asthma Control Assessment Tools. Respir Care. 2016;61(1):106-16.

5. Boonsawat W, Thompson PJ, Zaeoui U, Samosorn C, Acar G, Faruqi R, et al. Survey of asthma management in Thailand - the asthma insight and management study. Asian Pac J Allergy Immunol. 2015;33(1):14-20.

6. Taylor DR, Bateman ED, Boulet LP, Boushey HA, Busse WW, Casale TB, et al. A new perspective on concepts of asthma severity and control. Eur Respir J. 2008;32(3):545-54.

7. Global Initiative for Asthma. Global Strategy for Asthma Management and Prevention [Internet]. [Bethesda]: Global Initiative for Asthma; c2016 [cited 2018 Aug 13]. Available from: http://www.ginasthma.org

8. Nathan RA, Sorkness CA, Kosinski M, Schatz M, Li JT, Marcus P, et al. Development of the asthma control test: a survey for assessing asthma control. J Allergy Clin Immunol. 2004;113(1):59-65.

9. Schatz M, Sorkness CA, Li JT, Marcus P, Murray JJ, Nathan RA, et al. Asthma Control Test: reliability, validity, and responsiveness in patients not previously followed by asthma specialists. J Allergy Clin Immunol. 2006;117(3):549-56.

10. Vega JM, Badia X, Badiola C, Lopez-Vina A, Olaguibel JM, Picado C, et al. Validation of the Spanish version of the Asthma Control Test (ACT). J Asthma. 2007;44(10):867-72.

11. Zhou X, Ding FM, Lin JT, Yin KS, Chen P, He QY, et al. Validity of Asthma Control Test in Chinese patients. Chin Med J (Engl). 2007;120(12):1037-41.

12. Nguyen VN, Chavannes N, Le LT, Price D. The Asthma Control Test (ACT) as an alternative tool to Global Initiative for Asthma (GINA) guideline criteria for assessing asthma control in Vietnamese outpatients. Prim Care Respir J. 2012;21(1):85-9.

13. Olaguibel JM, Quirce S, Juliá B, Fernández C, Fortuna AM, Molina J, et al. Measurement of asthma control according to Global Initiative for Asthma guidelines: a comparison with the Asthma Control Questionnaire. Respir Res. 2012;13(1):50.

14. Uysal MA, Mungan D, Yorgancioglu A, Yildiz F, Akgun M, Gemicioglu B, et al. The validation of the Turkish version of Asthma Control Test. Qual Life Res. 2013;22(7):1773-9.

15. Sultan KM, Jamer AH, Obaidy MWA. Comparison of Asthma Control Test (ACT) with (GINA) guidelines in the Assessment of Asthma Control and determine if can use Asthmda Control Test ACT as alternative to Gina guidelines in control asthma. J Fac Med Baghdad. 2016;58(1):1-7.

16. Juniper EF, O’Byrne PM, Guyatt GH, Ferrie PJ, King DR. Development and validation of a questionnaire to measure asthma control. Eur Respir J. 1999;14(4):902-7.

17. Juniper EF, Buist AS, Cox FM, Ferrie PJ, King DR. Validation of a standardized version of the Asthma Quality of Life Questionnaire. Chest. 1999;115(5):1265-70.

18. Alvarez-Gutierrez FJ, Medina-Gallardo JF, Perez-Navarro P, Martin -Villasclaras JJ, Martin Etchegoren B, Romero-Romero B, et al. [Comparison of the Asthma Control Test (ACT) with lung function, levels of exhaled nitric oxide and control according to the Global Initiative for Asthma (GINA)]. Arch Bronconeumol. 2010;46(7):370-7. 
19. Sommanus S, Direkwattanachai C, Lawpoolsri S, Sitcharungsi R. Accuracy of childhood asthma control test among Thai childhood asthma patients. Asian Pac J Allergy Immunol. 2018;36(3):152-8.

20. Grammatopoulou EP, Stavrou N, Myrianthefs P, Karteroliotis K, Baltopoulos G, Behrakis P, et al. Validity and reliability evidence of the Asthma Control Test--ACT in Greece. J Asthma. 2011;48(1):57-64.

21. Roxo JPF, Ponte EV, Ramos DCB, Pimentel L, D’Oliveira Júnior A, Cruz ÁA. Validação do Teste de Controle da Asma em português para uso no Brasil: validation for use in Brazil. J Bras Pneumol. 2010;36:159-66.
22. Hasegawa T, Koya T, Sakagami T, Kagamu H, Arakawa M, Gejyo F, et al. The Asthma Control Test, Japanese version (ACT-J) as a predictor of Global Initiative for Asthma (GINA) guideline-defined asthma control: analysis of a questionnaire-based survey. Allergol Int. 2013;62(3):323-30.

23. Pothirat C, Chaiwong W, Phetsuk N, Liwsrisakun C, Bumroongkit C, Deesomchok A, et al. Dialectal influence on chronic pulmonary disease assessment test: the reliability and validity study. Int J Chron Obstruct Pulmon Dis. 2015;10:541-8.

24. Zhou X, Ding FM, Lin JT, Yin KS. Validity of asthma control test for asthma control assessment in Chinese primary care settings. Chest. 2009;135(4):904-10. 